\title{
The role of galenic innovation in improving treatment compliance and persistence: three case studies
}

This article was published in the following Dove Press journal:

ClinicoEconomics and Outcomes Research

3 August 20II

Number of times this article has been viewed

\author{
York Zoellner' \\ Maria-Magdalena Balp ${ }^{2}$ \\ Andrea Gili Marco ${ }^{2}$ \\ 'Hamburg University of Applied \\ Sciences, Hamburg, Germany; \\ ${ }^{2}$ Novartis Pharma AG, Basel, \\ Switzerland
}

Background: The purpose of this study was to explore whether newer galenic formulations with lower treatment burdens are associated with better patient compliance and persistence compared with older more burdensome modalities.

Methods: Data from the IMS Disease Analyzer database were analyzed retrospectively for two pairs of analogs (alendronate sodium once daily vs once weekly and immediate-release vs extended-release methylphenidate) and one pair of drugs with similar indications but important differences in convenience and dosing instructions (desferrioxamine vs deferasirox). Compliance was calculated as the sum of prescription durations for all prescriptions for each patient over 1 year. Persistence was calculated as the time between first and last prescriptions over 2 years (1 year for deferasirox and desferrioxamine). Data from Germany and the UK were available and used for analysis.

Results: Incremental improvements in compliance were $+30 \%$ in the UK and $+26 \%$ in Germany for alendronate once weekly vs once daily, $+14 \%$ in the UK and $+19 \%$ in Germany for extendedrelease vs immediate-release methylphenidate, and $+15 \%$ in Germany for desferrioxamine vs deferasirox. Incremental improvements in persistence were +9 months in the UK and +8 months in Germany for alendronate once weekly vs once daily, +4 months in the UK and +3 months in Germany for extended-release vs immediate-release methylphenidate, and +2 months in Germany for deferasirox vs desferrioxamine.

Conclusion: The new formulations that we evaluated were associated with better compliance and persistence compared with older formulations. Despite the fact that some sources of bias could not be excluded, it is likely that these improvements can be attributed to the lower treatment burdens of the galenic formulations of the drugs considered. Further investigation is required to confirm these findings and to determine whether new galenic formulations can improve health outcomes in routine clinical practice.

Keywords: galenic formulation, immediate-release methylphenidate, alendronate, deferasirox

\section{Introduction}

Advances in pharmacotherapy are typically perceived as being related to the availability of new molecular entities or compounds. However, there has been a gradual change in the way many stakeholders think about innovation in light of several scientific publications, ${ }^{1,2}$ official documents, ${ }^{3,4}$ and the use of value-based pricing in an increasing number of countries..$^{5}$ A more holistic view of innovation places less emphasis on developmental considerations, such as creation of new molecules (with whatever degree of structural novelty) and more emphasis on individual patients and society as a whole, with improvements in health outcomes driving research into, and rewards
Correspondence: York Zoellner Faculty of Life Sciences,

Department of Health Sciences, Lohbruegger Kirchstrasse 65, D-2 1033 Hamburg, Germany

Tel +49 40428756254

Fax +49 40428756129

Email yorkfrancis.zoellner@haw-hamburg.de 
for, pharmaceutical innovation. Such a system assesses the value of new molecules and galenic enhancements using the same terms of reference (ie, health outcomes).

While there is abundant clinical research comparing new molecules with placebo or an active comparator, there has traditionally been a lack of head-to-head comparisons between different galenic formulations of the same active molecule in "real-world" clinical practice. Therefore, there is little information available to describe the effects of new formulations on compliance and persistence despite the important effects of medication-taking behavior on clinical outcomes. Noncompliance with treatment and medical advice may cause accelerated disease, increased outpatient visits, more admissions to hospital, and impaired ability to predict the effectiveness of treatment. ${ }^{6}$ In addition, increased morbidity and mortality due to noncompliance may increase health care costs. ${ }^{7-10}$

Compliance is affected by numerous factors, which can be broadly classified as being related to the patient, society, and the treatment. ${ }^{11}$ Treatment-related factors include the mode of delivery, frequency of administration, and adverse effects. ${ }^{11}$ Reducing the burden of treatment, by simplifying treatment regimens for example, may have the potential to enhance compliance $^{11}$ and ultimately the outcomes of treatment. ${ }^{12-14}$ New formulations often have less complex regimens (eg, less frequent dosing) or more convenient routes of administration (eg, oral instead of intravenous infusion). However, while several studies have shown (for example) that once-daily treatments are associated with higher rates of compliance than more complex regimens, ${ }^{15-18}$ few studies have directly compared persistence and compliance between galenically different molecular analogs or near-analogs.

\section{Materials and methods Objective}

The objective of the study was to determine whether newer galenic formulations of drugs with lower treatment burdens are associated with better patient compliance and persistence compared with older more burdensome modalities. To explore the potential for new galenic formulations to improve compliance and persistence, we retrospectively reviewed data from the IMS Disease Analyzer database.

\section{Database content and selection of analogs}

The Intercontinental Medical Statistics (IMS) Disease Analyzer database includes data collected directly from computers in physicians' practices in Germany and the UK and provides daily routine information on patients' diseases and therapies, allowing tracking of prescription history. Each practice transmits patient data to IMS on a monthly basis. The database includes only anonymized data in compliance with applicable data protection legislation. The IMS Disease Analyzer database was reviewed to identify products that had undergone a formulation change with the potential to provide a major benefit for patients, such as improved convenience or reduced treatment burden. Products were considered for inclusion in the study if they were indicated for a condition that was associated with a high disease burden and required long-term treatment, and if their entries in the database included data on the timing and nature of prescriptions. Based on these criteria, three pairs of products were identified, ie, alendronate $\left(\right.$ Fosamax $\left.^{\circledR}\right)$ once daily and once weekly, methylphenidate immediate-release (Ritalin ${ }^{\circledR}$ ) and extended-release $\left(\right.$ Concerta $\left.^{\circledR}\right)$, and a pair of drugs with similar indications but important differences in convenience and dosing instructions (desferrioxamine [Desferal ${ }^{\circledR}$ ] and deferasirox [Exjade $\left.{ }^{\circledR}\right]$ ).

Alendronate once daily is indicated for prevention of fractures in men and postmenopausal women with osteoporosis, for treatment of glucocorticoid-induced osteoporosis, and to prevent bone loss in postmenopausal women at risk of osteoporosis. ${ }^{19}$ In Germany, alendronate once daily is indicated to reduce the risk of new vertebral and hip fractures in postmenopausal women without pre-existing vertebral fractures and for the treatment and prevention of glucocorticoid-induced osteoporosis in men and women not receiving estrogens, and is formulated as a $10 \mathrm{mg}$ oral tablet. ${ }^{20}$ Alendronate weekly is indicated for prevention of fractures in postmenopausal women with osteoporosis in the UK and Germany and is formulated as a $70 \mathrm{mg}$ oral tablet. ${ }^{21,22}$ Both alendronate products have restrictive dosing instructions. Tablets must be taken at least 30 minutes before the first food, beverage, or medicinal product of the day with plain water only. Patients must take the tablets with a full glass of water (at least $200 \mathrm{~mL}$ ) and must not lie down until after their first food of the day. The tablet must be swallowed whole and must not be crushed or chewed.

Immediate-release and extended-release methylphenidate are both indicated for management of attention-deficit hyperactivity disorder (ADHD) in children aged 6 years of age and older. ${ }^{23-25}$ Immediate-release methylphenidate is formulated as a $10 \mathrm{mg}$ tablet and requires careful dose titration, beginning once or twice daily (eg, at breakfast and lunch) 
with the dose and frequency increased up to a maximum of $60 \mathrm{mg}$ /day if required..$^{25} \mathrm{~A}$ small evening dose may be required if the effects wear off. Extended-release methylphenidate is formulated as an $18 \mathrm{mg}, 27 \mathrm{mg}$, or $36 \mathrm{mg}$ capsule-shaped tablet and must be swallowed whole with the aid of liquids, and must not be chewed, divided, or crushed. It may be administered with or without food and is taken once daily in the morning. ${ }^{23,24}$ Doses may be adjusted in $18 \mathrm{mg}$ increments starting with the lowest dose up to a maximum of $54 \mathrm{mg} /$ day.

Desferrioxamine is formulated as a sterile, lyophilized powder for reconstitution in a vial containing $500 \mathrm{mg}$ or $2 \mathrm{~g}$ of drug, ${ }^{26}$ whereas deferasirox is formulated as a dispersible $125 \mathrm{mg}, 250 \mathrm{mg}$, or $500 \mathrm{mg}$ tablet. ${ }^{27}$ In the UK, desferrioxamine is indicated for treatment of chronic iron overload, primary and secondary hemochromatosis, acute iron poisoning, and aluminum overload, and requires reconstitution before intravenous infusion, intramuscular injection, or subcutaneous infusion (the route of delivery depends on the condition being treated, with an average daily dose of $20-60 \mathrm{mg} / \mathrm{kg} /$ day adjusted based on initial monitoring of urinary ferritin). ${ }^{26}$ Deferasirox is indicated for chronic iron overload due to frequent blood transfusions in patients with beta thalassemia major aged 6 years and older and for treatment of chronic iron overload due to blood transfusions when desferrioxamine therapy is contraindicated or inadequate. It is administered once daily on an empty stomach at least 30 minutes before food, preferably at the same time each day, usually at an initial dose of $20 \mathrm{mg} / \mathrm{kg}$ with adjustments in 5-10 mg/kg increments based on monitoring of serum ferritin. ${ }^{27}$ In Germany, deferasirox is indicated for the management of chronic iron overload due to frequent transfusions in patients with beta thalassemia major over 6 years of age and for the management of chronic transfusional iron overload. ${ }^{28}$ The tablets are dispersed by stirring in a glass of water or orange or apple juice. Any residue remaining in the glass must be resuspended in a small volume of water or juice and swallowed.

\section{Data retrieval and analysis}

Data were retrieved from the IMS Disease Analyzer database. Records were available for patients treated in the UK and Germany. Analyses of alendronate and methylphenidate included patients from the UK and Germany. Analysis of desferrioxamine and deferasirox was restricted to patients from Germany, because complete data were not available for patients receiving these products in the UK. All patients receiving any of the products were included in the analyses.
Patients included in the analysis had to be initiated on the formulation of interest and not received any previous prescription for the same combination of substance and formulation. Patients had to have treatment initiated between January 2003 and December 2007 in order to provide for a follow-up period of at least 2 years at the time of analysis (December 2009). For each patient included in the analysis, information was retrieved from the database to identify the substance, formulation, and dose. Dates of prescriptions, quantity of medication, dosage, and prescription duration were used to calculate compliance and persistence.

Compliance is generally defined as the act of following the treatment recommendations made by the prescriber in terms of dose and frequency of medication. ${ }^{29}$ It is measured over a period of time and is expressed as a percentage. In our study, compliance was calculated as the sum of the durations of prescribed treatments for an individual patient over a 1 -year period. For the chronic conditions considered in our analyses, it was assumed that patients required treatment continuously throughout the study period and that gaps in the prescribing history reflected noncompliance. The 1-year period was selected to capture sufficient prescription data without biasing the results by including patients who had stopped using the drug (as would have been the case if longer time periods had been used).

Persistence is generally defined as the duration of treatment from initiation until discontinuation and can be reported as a continuous variable (number of days for which the medication was available) or a dichotomous variable (persistent or nonpersistent) at the end of the observation period. ${ }^{29}$ In our study, treatment periods evaluated for persistence were calculated as the time between the first and last prescription using the quantity prescribed and dosage instruction issued by the doctor. A 2-year time period was used for analysis of persistence to account for patients using the drugs for periods of time greater than the 1-year period used for analysis of compliance. However, due to the recent introduction of deferasirox at the time of analysis, data were not available for 2 years and persistence was therefore calculated over 1 year for both deferasirox and desferrioxamine. As per definition, gaps in prescribed treatment were not taken into account for the analysis of persistence. Patients were considered nonpersistent if they stopped taking the medication for any reason, including switching to another medication or no longer requiring treatment. A patient was defined as having stopped medication if he or she had no current prescription for that medication at the time of analysis. 


\section{Results}

For alendronate once daily and weekly, data on persistence and compliance were retrieved for 595 and 13,468 patients, respectively, in the UK, and 554 and 8941, respectively, in Germany. For immediate-release and extended-release methylphenidate, data were retrieved for 449 and 590 patients, respectively, in the UK, and 594 and 483, respectively, in Germany. For desferrioxamine and deferasirox, data were retrieved for 518 and 2229 patients, respectively, in Germany.

\section{Compliance}

For all three pairs of products, compliance was higher with the newer formulations than with the original agents (Table 1). Absolute incremental improvements in compliance over 1 year were $+30 \%$ in the UK and $+26 \%$ in Germany for alendronate once weekly vs once daily, $+14 \%$ in the UK and $+19 \%$ in Germany for extended-release vs immediate-release methylphenidate, and $+15 \%$ in Germany for desferrioxamine vs deferasirox. Among patients receiving alendronate once daily, 33\% in the UK and 40\% in Germany took their medication for $0 \%-10 \%$ of the time during the first year, compared with $10 \%$ and $17 \%$, respectively, for alendronate weekly. Higher percentages of patients receiving alendronate weekly (52\% in the UK and 33\% in Germany) took their medication at least $90 \%$ of the time over 1 year, compared with those receiving alendronate once daily ( $21 \%$ in the UK and $14 \%$ in Germany). Similarly, $15 \%$ of immediate-release methylphenidate recipients in the UK and $39 \%$ in Germany took their medication for $0 \%-10 \%$ of the time, compared with $9 \%$ and $16 \%$, respectively, for extendedrelease methylphenidate. Patients receiving extended-release

Table I Mean compliance over I year

\begin{tabular}{llll}
\hline & \multicolumn{2}{l}{ Compliance (\%) } & $\begin{array}{l}\text { Incremental } \\
\text { compliance (\%) }\end{array}$ \\
\cline { 2 - 3 } & $\begin{array}{l}\text { Older } \\
\text { formulation }\end{array}$ & $\begin{array}{l}\text { Newer } \\
\text { formulation }\end{array}$ & \\
\hline Alendronate $^{\mathrm{a}}$ & 40 & 70 & +30 \\
$\quad$ UK & 29 & 55 & +26 \\
$\quad$ Germany & 54 & 68 & +14 \\
$\begin{array}{l}\text { Methylphenidate } \\
\text { b }\end{array}$ & & 46 & +19 \\
$\quad$ UK & 27 & & \\
$\quad$ Germany & & 46 & +15 \\
$\begin{array}{l}\text { Desferrioxamine/ } \\
\text { deferasirox }\end{array}$ & & & \\
Germany & 31 & &
\end{tabular}

Notes: ${ }^{a}$ Alendronate once daily (older formulation) vs alendronate weekly (newer formulation); 'immediate-release methylphenidate (older formulation) vs extendedrelease methylphenidate (newer formulation); 'desferrioxamine (older formulation) vs deferasirox (newer formulation). methylphenidate were more likely to take their medication at least $90 \%$ of the time over 1 year $(46 \%$ in the UK and $17 \%$ in Germany), compared with patients receiving immediate-release methylphenidate (28\% in the UK and $5 \%$ in Germany). Among patients receiving desferrioxamine in Germany, $47 \%$ took their medication for $0 \%-10 \%$ of the time during the first year, compared with $26 \%$ for deferasirox. Similar percentages of German patients receiving deferasirox $(16 \%)$ and desferrioxamine (14\%) took their medication at least $90 \%$ of the time over 1 year.

\section{Persistence}

Persistence was higher for all three newer formulations, compared with the respective older formulations (Table 2). Incremental improvements in persistence over 2 years were +9 months in the UK and +8 months in Germany for alendronate once weekly vs once daily, +4 months in the UK and +3 months in Germany for extended-release vs immediate-release methylphenidate, and +2 months in Germany for deferasirox vs desferrioxamine. Among patients receiving alendronate weekly, $63 \%$ in the UK and $42 \%$ in Germany took their medication for at least 2 years, compared with $22 \%$ and $12 \%$, respectively, for alendronate once daily. Patients receiving alendronate weekly were less likely to stop taking their medication during the first 2 months $(12 \%$ in the UK and $17 \%$ in Germany), compared with alendronate once daily (41\% in the UK and 54\% in Germany). Similarly, 69\% of extended-release methylphenidate recipients in the UK and $41 \%$ in Germany took their medication for at least 2 years, compared with $42 \%$ and $32 \%$, respectively, for immediaterelease methylphenidate. The percentage of patients who stopped taking their medication during months 1 or 2 was

Table 2 Mean persistence over 2 years

\begin{tabular}{|c|c|c|c|}
\hline & \multicolumn{2}{|c|}{ Persistence (months) } & \multirow{2}{*}{$\begin{array}{l}\text { Incremental } \\
\text { compliance } \\
\text { (months) }\end{array}$} \\
\hline & $\begin{array}{l}\text { Older } \\
\text { formulation }\end{array}$ & $\begin{array}{l}\text { Newer } \\
\text { formulation }\end{array}$ & \\
\hline \multicolumn{4}{|c|}{ Alendronate ${ }^{\mathrm{a}}$} \\
\hline UK & 9 & 18 & +9 \\
\hline Germany & 6 & 14 & +8 \\
\hline \multicolumn{4}{|c|}{ Methylphenidate ${ }^{\mathrm{b}}$} \\
\hline UK & 15 & 19 & +4 \\
\hline Germany & II & 14 & +3 \\
\hline \multicolumn{4}{|c|}{$\begin{array}{l}\text { Desferrioxamine/ } \\
\text { deferasirox }^{c}\end{array}$} \\
\hline Germany & 5 & 7 & +2 \\
\hline
\end{tabular}

Notes: aAlendronate once daily (older formulation) vs alendronate weekly (newer formulation); bimmediate-release methylphenidate (older formulation) vs extendedrelease methylphenidate (newer formulation); ' desferrioxamine (older formulation) vs deferasirox (newer formulation). 
lower with extended-release methylphenidate $(9 \%$ in the UK and $25 \%$ in Germany) than with immediate-release methylphenidate (18\% in the UK and $37 \%$ in Germany). Among patients receiving deferasirox in Germany, 31\% took their medication for over 2 years, compared with $25 \%$ for desferrioxamine. In Germany, fewer patients stopped taking deferasirox (29\%) during months 1 and 2, compared with desferrioxamine (38\%).

\section{Discussion}

Our analyses indicate that, for the three selected pairs of products, newer agents with improved galenic formulations were associated with higher rates of compliance and persistence than older formulations. Newer products (alendronate weekly, extended-release methylphenidate, and deferasirox) were associated with incremental improvements in 1-year compliance of between $14 \%$ and $30 \%$ vs older products (alendronate once daily, immediate-release methylphenidate, and desferrioxamine). The newer products were also associated with higher mean persistence (increments of 2-9 months) compared with the older products. The difference in compliance and persistence between the methylphenidate formulations occurred despite the fact that placebo-controlled studies have indicated that some adverse events (especially insomnia) may be more frequent with longer-acting products. ${ }^{30}$ Therefore, our findings indicate that the greater convenience of extendedrelease methylphenidate may outweigh possible disadvantages related to a higher incidence of adverse effects.

The differences in compliance and persistence between deferasirox and desferrioxamine were smaller than the differences between weekly and once-daily alendronate or between extended-release and immediate-release methylphenidate. The smaller difference in persistence may have been related to the shorter assessment period used in patients receiving deferasirox and desferrioxamine (1 year) compared with the other pairs of products ( 2 years). The smaller difference between deferasirox and desferrioxamine, compared with the differences between weekly and oncedaily alendronate, may also have been related to the fact that many patients who require deferasirox or desferrioxamine for beta thalassemia are children who will be assisted by their parents when taking the medication. This assistance may have increased rates of compliance and persistence. However, many patients receiving methylphenidate are young children, so it is unlikely that differences in parental assistance could explain the difference between deferasirox and desferrioxamine, compared with the difference between immediate-release and extended-release methylphenidate.
The higher compliance and persistence associated with the newer formulations might be related to a lower treatment burden compared with the older products. For example, alendronate has restrictive dosing instructions, and the difference in dosing frequency between formulations might result in a lower burden for patients receiving the weekly formulation, compared with daily dosing. Similarly, extended-release methylphenidate is given once daily at breakfast whereas immediate-release methylphenidate is given up to three times a day, requiring children to take the tablets during their school day. Deferasirox is also easier to administer (dispersed in water or fruit juice) than desferrioxamine (reconstituted and infused using a pump for five nights per week).

While the aforementioned causal attribution appears plausible, several limitations of the study should be noted. Our findings indicate that the newer treatments were associated with higher compliance and persistence than the older treatments. However, the possibility that these findings were due to differences between the populations being prescribed each product, rather than to the products themselves, cannot be ruled out. No data are available to determine whether there were meaningful differences between the patient populations. Because this was a retrospective study, the patients were not randomized to the various treatment groups and there may have been differences between the populations receiving the newer vs the older formulations. For example, physicians may have been more inclined to prescribe newer formulations to certain patients (eg, those with more severe disease) than to others (selection bias). Having said that, it appears unclear in which direction (overestimation or underestimation) this bias would work. Further, our analysis could not adjust for the influence of industry-driven promotion and disease education, which may also affect the uptake of newer treatments.

Although the IMS database provides a representative sample of German and UK patient populations, it should also be noted that our findings may not be applicable to other countries. It is also important to note that our assessments of compliance and persistence were based on the number of prescriptions and did not take account of whether patients actually filled the prescription or took the medication. Therefore, our analyses may have overestimated both compliance and persistence. Assuming that both arms of each pair-wise comparison were affected equally by a potential overestimation, this would not have affected the incremental analysis. However, as mentioned before, any potential selection effects are unclear or unknown. 
While our study did not directly assess the burden associated with each treatment, several other studies have indicated that newer formulations are associated with improved patient satisfaction and quality of life, compared with older formulations. For example, patients receiving deferasirox have been shown to have improved satisfaction and quality of life, lower levels of anxiety and depression, and higher compliance, compared with previous treatments. ${ }^{31-38} \mathrm{In}$ addition, a study of patients receiving iron chelating therapy (injected or oral) showed that four variables were significant predictors of never thinking about stopping treatment, ie, age, perceived effectiveness of therapy, burden of therapy, and low incidence of adverse effects. ${ }^{39}$ Studies have also shown that weekly or monthly dosing with bisphosphonates (alendronate or ibandronate) is preferred by many patients, compared with daily dosing, ${ }^{40-42}$ and that weekly alendronate is associated with higher compliance than daily bisphosphonates. ${ }^{43}$

If reformulation of a product results in improved compliance and persistence, it would be reasonable to hypothesize that there might be an associated improvement in efficacy. A small number of studies have compared extendedrelease and immediate-release methylphenidate, including two that showed that switching from immediate-release to extended-release methylphenidate improved symptom control in children and adolescents with ADHD. ${ }^{44,45}$ There was also an improvement in compliance after the switch in one of these studies; ${ }^{44}$ no data on compliance were provided in the published results from the other study. ${ }^{45}$ In addition, a study of children with ADHD who were poorly compliant with immediate-release methylphenidate showed that, after switching to extended-release methylphenidate, $72 \%$ of children had good compliance. ${ }^{46}$ This improvement was accompanied by improvements in symptom control. However, a randomized study in children with ADHD showed that the two methylphenidate formulations had similar efficacy, despite a slightly higher completion rate with extended-release methylphenidate $(81 \%)$ than with the immediate-release formulation (75\%). ${ }^{47}$ In contrast, another study in children with ADHD showed that extended-release methylphenidate was more effective than immediate-release methylphenidate, but there was no difference in discontinuation rates during the study. ${ }^{48}$ Overall, these studies indicate that switching from immediate-release to extended-release methylphenidate may improve compliance, but it remains unclear whether increases in compliance or persistence translate into improved efficacy in routine clinical practice.

Several studies have compared deferasirox and desferrioxamine. A study in patients with transfusional iron overload due to sickle cell disease showed that deferasirox and desferrioxamine resulted in similar reductions in liver iron concentration. ${ }^{49}$ Discontinuation rates were similar between deferasirox (11.4\%) and desferrioxamine (11.1\%). ${ }^{49}$ Efficacy (reduction in liver iron concentration) was also similar between deferasirox and desferrioxamine in a study of patients with transfusional iron overload due to thalassemia, although no information on discontinuation rates was provided in the publication from that study. ${ }^{50}$

Comparisons of alendronate weekly (70 $\mathrm{mg}$ or $35 \mathrm{mg}$ once weekly) and once daily (10 mg or $5 \mathrm{mg}$ ) have shown that the two products are therapeutically equivalent and have similar safety and tolerability. ${ }^{51-53}$ However, there have been no studies comparing the efficacy of the two formulations in a "real-world" setting.

\section{Conclusion}

Our analysis indicates that the reduced treatment burdens attributed to new galenic formulations which we evaluated against their older counterparts are associated with better compliance and persistence. Further investigation, with different study designs and the inclusion of additional control variables, is required to confirm these findings and to evaluate the extent to which new galenic formulations can ultimately improve health outcomes in routine clinical practice.

\section{Disclosure}

This study was funded by Novartis Pharma AG, Basel, Switzerland. M-MB and AGM are employees of Novartis. The authors were assisted in the preparation of the manuscript by Paul Hutchin, a professional medical writer contracted to ACUMED ${ }^{\circledR}$ and funded by Novartis. Editorial assistance was provided by Helen Venables (ACUMED ${ }^{\circledR}$ ), funded by Novartis.

\section{References}

1. Stafford RS, Wagner TH, Lavori PW. New, but not improved? Incorporating comparative-effectiveness information into FDA labeling. N Engl J Med. 2009;361:1230-1233.

2. Stiglitz JE, Jayadev A. Medicine for tomorrow: some alternative proposals to promote socially beneficial research and development in pharmaceuticals. Journal of Generic Medicines. 2010;7:217-226.

3. [German Pharmaceutical Society] Blume H, Brauer K, Dingermann T, et al, on behalf of the expert group "drug innovation". Criteria for the evaluation of drug innovations. Position paper. Pharmazeutische Zeitung. 2005;150 Suppl :1-42. Available at: http://www.dphg.de/includes/upload/ DPhG-Positionspapier.pdf. Accessed July 12, 2011. German.

4. Kennedy I. Appraising the value of innovation and other benefits a short study for NICE. 2009. Available from: http://www.nice.org.uk/ media/98F/5C/KennedyStudyFinalReport.pdf. Accessed July 5, 2010.

5. Willis M, Persson U, Zoellner Y, Gradl B. Reducing uncertainty in value-based pricing using evidence development agreements: the case of continuous intraduodenal infusion of levodopa/carbidopa (Duodopa[R]) in Sweden. Appl Health Econ Health Policy. 2010;8:377-386. 
6. Abbott J, Dodd M, Bilton D, Webb AK. Treatment compliance in adults with cystic fibrosis. Thorax. 1994;49:115-120.

7. Gorenoi V, Schonermark MP, Hagen A. Interventions for enhancing medication compliance/adherence with benefits in treatment outcomes. GMS Health Technol Assess. 2008;3:Doc14.

8. Marceau C, Lemiere C, Berbiche D, Perreault S, Blais L. Persistence, adherence, and effectiveness of combination therapy among adult patients with asthma. J Allergy Clin Immunol. 2006;118: 574-581.

9. Yang W, Chang J, Kahler KH, et al. Evaluation of compliance and health care utilization in patients treated with single pill vs free combination antihypertensives. Curr Med Res Opin. 2010;26:2065-2076.

10. Brixner DI, Ye X, Chu TC, Blumentals WA, Hassanein TI. Treatment persistence in and cost of therapy for patients with chronic hepatitis $\mathrm{C}$ : peginterferon alfa-2a plus ribavirin versus peginterferon alfa- $2 \mathrm{~b}$ plus ribavirin. Am J Health Syst Pharm. 2009;66:2171-2178.

11. Lareau SC, Yawn BP. Improving adherence with inhaler therapy in COPD. Int J Chron Obstruct Pulmon Dis. 2010;5:401-406.

12. Elliott WJ. Improving outcomes in hypertensive patients: focus on adherence and persistence with antihypertensive therapy. $J$ Clin Hypertens (Greenwich). 2009;11:376-382.

13. Restrepo RD, Alvarez MT, Wittnebel LD, et al. Medication adherence issues in patients treated for COPD. Int J Chron Obstruct Pulmon Dis 2008;3:371-384

14. Siris ES, Selby PL, Saag KG, Borgstrom F, Herings RM, Silverman SL. Impact of osteoporosis treatment adherence on fracture rates in North America and Europe. Am J Med. 2009;122(Suppl 2): S3-S13.

15. Bourbeau J, Bartlett SJ. Patient adherence in COPD. Thorax. 2008;63: 831-838.

16. Price D, Robertson A, Bullen K, Rand C, Horne R, Staudinger H. Improved adherence with once-daily versus twice-daily dosing of mometasone furoate administered via a dry powder inhaler: a randomized open-label study. BMC Pulm Med. 2010;10:1.

17. Raboud J, Li M, Walmsley S, et al. Once daily dosing improves adherence to antiretroviral therapy. AIDS Behav. 2010. [Epub ahead of print].

18. Yentzer BA, Ade RA, Fountain JM, et al. Simplifying regimens promotes greater adherence and outcomes with topical acne medications: a randomized controlled trial. Cutis. 2010;86:103-108.

19. Fosamax SmPC. Summary of product characteristics. 2010. Available from: http://www.medicines.org.uk/EMC/medicine/1175/SPC/ Fosamax/\#INDICATIONS. Accessed June 15, 2011.

20. Gelbe Liste Pharmindex. Fosamax. 2011. Available from: http://www. gelbe-liste.de/pharmindex/praeparat/bi/fosamax-10 mg-tbl-msd-sharpdohme-gmbh/\#top. Accessed April 4, 2011.

21. Fosamax weekly SmPC. Summary of product characteristics. 2010 Available from: http://www.medicines.org.uk/EMC/medicine/4115/ $\mathrm{SPC} /$ Fosamax+Once+Weekly+70 mg+Tablets/\#INDICATIONS. Accessed June 15, 2011

22. Gelbe Liste Pharmindex. [Fosamax once weekly]. 2011. Available from: http://www.gelbe-liste.de/pharmindex/praeparat/bi/fosamax-einmalwoechentlich-70mg-tbl-msd-sharp-dohme-gmbh/. Accessed April 4, 2011. Password-protected - access restricted to registered health care professionals.

23. Concerta 18-36 mg SmPC. Summary of product characteristics. 2010. Available from: http://www.medicines.org.uk/EMC/medicine/8382/ $\mathrm{SPC} /$ Concerta $+\mathrm{XL}+18+\mathrm{mg}+-+36+\mathrm{mg}+$ prolonged+release+tablets/. Accessed June 15, 2011.

24. Concerta $27 \mathrm{mg}$ SmPC. Summary of product characteristics. 2010. Available from: http://www.medicines.org.uk/EMC/medicine/19549/SPC/ Concerta $+\mathrm{XL}+27+\mathrm{mg}+$ prolonged-release+tablets/\#INDICATIONS. Accessed June 15, 2011

25. Ritalin SmPC. Summary of product characteristics. 2010. Available from: http://www.medicines.org.uk/EMC/medicine/1316/SPC/ Ritalin/\#FORM. Accessed January 24, 2011.

26. Desferal SmPC. Summary of product characteristics. 2010. Available from: http://www.medicines.org.uk/EMC/medicine/2666/SPC/Desfer al+Vials\%2c+500 mg+or+2 g/\#FORM. Accessed June 15, 2011.
27. Exjade SmPC. Summary of product characteristics. 2011. Available from: http://www.medicines.org.uk/EMC/medicine/18805/SPC/EXJ $\mathrm{ADE}+125+\mathrm{mg} \% 2 \mathrm{c}+250 \mathrm{mg} \% 2 \mathrm{c}+500 \mathrm{mg}+$ dispersible+tablets/\#FORM. Accessed June 15, 2011.

28. Gelbe Liste Pharmindex. Exjade. 2011. Available from: http://www. gelbe-liste.de/pharmindex/praeparat/bi/exjade-125-mg-tablettenzur-herstellung-einer-suspension-zum-einnehmen-novartis-pharmagmbh/. Accessed April 4, 2011.

29. Cramer JA, Roy A, Burrell A, et al. Medication compliance and persistence: terminology and definitions. Value Health. 2008;11: 44-47.

30. Merkel RL Jr, Kuchibhatla A. Safety of stimulant treatment in attention deficit hyperactivity disorder: part I. Expert Opin Drug Saf. 2009;8: 655-668.

31. Porter JB, Athanasiou-Metaxa M, Bowen DK, et al. Improved patient satisfaction, adherence and health-related quality of life with deferasirox $\left(E x_{j a d e}{ }^{\circledR}\right)$ in beta-thalassemia patients previously receiving other iron chelation therapies. Blood. 2009;114:980-981.

32. Yamashita R, Sobota A, Trachtenberg F, et al. The impact of the child with thalassemia on the family: parental assessment by child health questionnaire. Blood. 2009;114:558.

33. Mednick L, Yu S, Trachtenberg F, et al. Symptoms of anxiety and depression among teens and adults in the thalassemia longitudinal cohort study. Blood. 2009;114:231-232.

34. Porter JB, Bowden D, Ganser A, et al. Satisfaction and adherence significantly improves in patients with beta-thalassemia and myelodysplastic syndromes treated with deferasirox. Blood. 2008; 112:472.

35. Vichinsky E, Pakbaz Z, Onyekwere O, et al. Patient-reported outcomes of deferasirox (Exjade, ICL670) versus deferoxamine in sickle cell disease patients with transfusional hemosiderosis. Substudy of a randomized open-label phase II trial. Acta Haematol. 2008;119:133-141.

36. Osborne RH, De Abreu LR, Dalton A, et al. Quality of life related to oral versus subcutaneous iron chelation: a time trade-off study. Value Health. 2007;10:451-456.

37. Cappellini MD, Bejaoui M, Agaoglu L, et al. Prospective evaluation of patient-reported outcomes during treatment with deferasirox or deferoxamine for iron overload in patients with beta-thalassemia. Clin Ther. 2007;29:909-917.

38. Delea TE, Sofrygin O, Thomas SK, Baladi JF, Phatak PD, Coates TD Cost effectiveness of once-daily oral chelation therapy with deferasirox versus infusional deferoxamine in transfusion-dependent thalassaemia patients: US healthcare system perspective. Pharmacoeconomics. 2007; 25:329-342.

39. Rofail D, Abetz L, Viala M, Gait C, Baladi JF, Payne K. Satisfaction and adherence in patients with iron overload receiving iron chelation therapy as assessed by a newly developed patient instrument. Value Health. 2009;12:109-117.

40. Bock O, Felsenberg D. Bisphosphonates in the management of postmenopausal osteoporosis - optimizing efficacy in clinical practice. Clin Interv Aging. 2008;3:279-297.

41. Kendler D, Kung AW, Fuleihan G, et al. Patients with osteoporosis prefer once weekly to once daily dosing with alendronate. Maturitas. 2004;48:243-251.

42. Simon JA, Lewiecki EM, Smith ME, Petruschke RA, Wang L, Palmisano JJ. Patient preference for once-weekly alendronate $70 \mathrm{mg}$ versus once-daily alendronate $10 \mathrm{mg}$ : a multicenter, randomized, openlabel, crossover study. Clin Ther. 2002;24:1871-1886.

43. Cramer JA, Amonkar MM, Hebborn A, Altman R. Compliance and persistence with bisphosphonate dosing regimens among women with postmenopausal osteoporosis. Curr Med Res Opin. 2005;21: $1453-1460$

44. Hoare P, Remschmidt H, Medori R, et al. 12-month efficacy and safety of OROS MPH in children and adolescents with attentiondeficit/hyperactivity disorder switched from MPH. Eur Child Adolesc Psychiatry. 2005;14:305-309. 
45. Remschmidt H, Hoare P, Ettrich C, et al. Symptom control in children and adolescents with attention-deficit/hyperactivity disorder on switching from immediate-release MPH to OROS MPH Results of a 3-week open-label study. Eur Child Adolesc Psychiatry. 2005;14: 297-304.

46. Chou WJ, Chou MC, Tzang RF, et al. Better efficacy for the osmotic release oral system methylphenidate among poor adherents to immediate-release methylphenidate in the three ADHD subtypes. Psychiatry Clin Neurosci. 2009;63:167-175.

47. Biederman J, Mick EO, Surman C, et al. Comparative acute efficacy and tolerability of OROS and immediate release formulations of methylphenidate in the treatment of adults with attention-deficit/ hyperactivity disorder. BMC Psychiatry. 2007;7:49.

48. Steele M, Weiss M, Swanson J, Wang J, Prinzo RS, Binder CE. A randomized, controlled effectiveness trial of OROS-methylphenidate compared to usual care with immediate-release methylphenidate in attention deficit-hyperactivity disorder. Can J Clin Pharmacol. 2006;13: e50-e62.

49. Vichinsky E, Onyekwere O, Porter J, et al. A randomised comparison of deferasirox versus deferoxamine for the treatment of transfusional iron overload in sickle cell disease. Br J Haematol. 2007;136:501-508.
50. Piga A, Galanello R, Forni GL, et al. Randomized phase II trial of deferasirox (Exjade, ICL670), a once-daily, orally-administered iron chelator, in comparison to deferoxamine in thalassemia patients with transfusional iron overload. Haematologica. 2006;91:873-880.

51. Luckey MM, Gilchrist N, Bone HG, et al. Therapeutic equivalence of alendronate 35 milligrams once weekly and 5 milligrams daily in the prevention of postmenopausal osteoporosis. Obstet Gynecol. 2003;101: 711-721.

52. Schnitzer T, Bone HG, Crepaldi G, et al. Therapeutic equivalence of alendronate $70 \mathrm{mg}$ once-weekly and alendronate $10 \mathrm{mg}$ daily in the treatment of osteoporosis. Alendronate once-weekly study group. Aging (Milano). 2000;12:1-12.

53. Uchida S, Taniguchi T, Shimizu T, et al. Therapeutic effects of alendronate $35 \mathrm{mg}$ once weekly and $5 \mathrm{mg}$ once daily in Japanese patients with osteoporosis: a double-blind, randomized study. $J$ Bone Miner Metab. 2005;23:382-388.
ClinicoEconomics and Outcomes Research

\section{Publish your work in this journal}

ClinicoEconomics \& Outcomes Research is an international, peerreviewed open-access journal focusing on Health Technology Assessment, Pharmacoeconomics and Outcomes Research in the areas of diagnosis, medical devices, and clinical, surgical and pharmacological intervention. The economic impact of health policy and health systems

\section{Dovepress}

organization also constitute important areas of coverage. The manuscript management system is completely online and includes a very quick and fair peer-review system, which is all easy to use. Visit http://www.dovepress.com/testimonials.php to read real quotes from published authors. 